\title{
Malignant pheochromocytoma: current status and initiatives for future progress
}

\author{
Graeme Eisenhofer $^{1}$, Stefan R Bornstein ${ }^{2}$, Frederieke M Brouwers ${ }^{1}$, \\ Nai-Kong V Cheung ${ }^{3}$, Patricia L Dahia ${ }^{4}$, Ronald $R$ de Krijger ${ }^{5}$, \\ Thomas J Giordano ${ }^{6}$, Lloyd A Greene ${ }^{7}$, David S Goldstein", \\ Hendrik Lehnert ${ }^{8}$, William M Manger ${ }^{9}$, John M Maris ${ }^{10}$, \\ Hartmut P H Neumann ${ }^{11}$, Karel Pacak ${ }^{1}$, Barry L Shulkin ${ }^{7}$, \\ David I Smith ${ }^{12}$, Arthur S Tischler ${ }^{13}$ and William F Young Jr ${ }^{12}$
}

\author{
${ }^{1}$ National Institutes of Health, Bethesda, Maryland, USA \\ ${ }^{2}$ University of Düsseldorf, Düsseldorf, Germany \\ ${ }^{3}$ Memorial Sloan-Kettering Cancer Center, New York, New York, USA \\ ${ }^{4}$ Dana-Farber Cancer Institute, Boston, Massachusetts, USA \\ ${ }^{5}$ Erasmus Medical Center, Rotterdam, the Netherlands \\ ${ }^{6}$ University of Michigan, Ann Arbor, Michigan, USA \\ ${ }^{7}$ Columbia University, New York, New York, USA \\ ${ }^{8}$ Magdeburg University Medical School, Magdeburg, Germany \\ ${ }^{9}$ National Hypertension Association, New York, New York, USA \\ ${ }^{10}$ University of Pennsylvania School of Medicine, Philadelphia, Pennsylvania, USA \\ ${ }^{11}$ Medizinische Universitätsklinik, Freiburg, Germany \\ ${ }^{12}$ Mayo Clinic, Rochester, Minnesota, USA \\ ${ }^{13} \mathrm{New}$ England Medical Center, Boston, Massachusetts, USA
}

(Requests for offprints should be addressed to G Eisenhofer, Building 10, Room 6N252, National Institutes of Health, 10 Center Drive MSC 1620, Bethesda MD 20892-1620, USA; Email: ge@ box-g.nih.gov)

\begin{abstract}
Pheochromocytomas are rare catecholamine-producing neuroendocrine tumors that are usually benign, but which may also present as or develop into a malignancy. Predicting such behavior is notoriously difficult and there are currently no curative treatments for malignant tumors. This report follows from a workshop at the Banbury Conference Center, Cold Spring Harbor, New York, on the 16th-18th November 2003, held to review the state of science and to facilitate future progress in the diagnosis and treatment of malignant pheochromocytoma. The rarity of the tumor and the resulting fragmented nature of studies, typically involving small numbers of patients, represent limiting factors to the development of effective treatments and diagnostic or prognostic markers for malignant disease. Such development is being facilitated by the availability of new genomics-based tools, but for such approaches to succeed ultimately requires comprehensive clinical studies involving large numbers of patients, stringently collected clinical data and tumor samples, and interdisciplinary collaborations among multiple specialist centers. Nevertheless, the well-characterized hereditary basis and the unique functional nature of these neuroendocrine tumors provide a useful framework that offers advantages for establishing the pathways of tumorigenesis and malignancy. Such findings may have relevance for understanding the basis of other more common malignancies where similar frameworks are not available. As the relevant pathways leading to pheochromocytoma are established it should be possible to take advantage of the new generation of drugs being developed to target specific pathways in other malignancies. Again the success of this will require well-designed and coordinated multicenter studies.
\end{abstract}

Endocrine-Related Cancer (2004) 11 423-436 


\section{Introduction}

Pheochromocytomas are tumors arising from chromaffin cells, mainly of the adrenal gland, that synthesize, store, metabolize, and usually but not always secrete catecholamines (Manger \& Gifford 1996). Most are benign and curable by surgical resection, but some are clinically malignant (Lehnert et al. 2004). Although the prevalence of malignancy is commonly cited at about $10 \%$, other estimates suggest rates of between 5-26\% depending on how malignancy is defined, with lower or even higher values in certain patient groups depending on the underlying mutation (Goldstein et al. 1999, Edstrom Elder et al. 2003, Gimenez-Roqueplo et al. 2003).

Currently, there is no effective cure for malignant pheochromocytoma. There are also no reliable histopathological methods for distinguishing benign from malignant tumors. Instead, malignancy requires evidence of metastases at non-chromaffin sites distant from that of the primary tumor. Although extensive invasion of adjacent tissues can be considered an indicator of malignant potential, local invasiveness and malignant disease are not necessarily associated. The presence of metastases provides the only currently widely accepted means to define malignant pheochromocytoma.

Because there is no cure for malignant pheochromocytoma, nor reliable prognostic or histopathologic diagnostic markers of malignancy, establishing the pathways of tumorigenesis and malignancy in pheochromocytoma represent important objectives that can take advantage of the well-characterized functional nature and genetic background of these tumors and the wealth of information available about chromaffin cell biology. Apart from development of useful diagnostic and prognostic markers and effective therapies, the findings so obtained might also have broader implications for other malignancies. However, due to the rarity of the tumor, clinical studies about pheochromocytoma suffer from a fragmented nature and usually involve too small a number of cases to reach conclusive results. This undoubtedly contributes to the relatively poor state of funding for clinical research about pheochromocytoma (Table 1) and consequently also limits progress for new diagnostic or prognostic markers and treatments for malignant disease.

In July 2003, Drs James Watson and William Manger met at Cold Spring Harbor Laboratory to discuss the need to differentiate malignant from benign pheochromocytomas on a molecular basis. The workshop held between the 16th and 18th November 2003 at the Banbury Conference Center, Cold Spring Harbor brought together a select group of experts in the field to present data and discuss the current state of knowledge and research about malignant pheochromocytoma. The workshop focused on applications of new genomics-based tools for establishing the pathways involved in the development of pheochromocytoma and for identifying molecular targets for diagnosis, prognosis, and treatment of malignancy in patients with these neuroendocrine tumors. An important objective of the workshop was to establish a consortium of investigators for a coordinated and concerted evidencebased approach to future studies of pheochromocytoma.

Such a consortium approach is already underway for studies of neuroblastoma, which although closely related to pheochromocytoma and overall almost as rare, is one of

Table 1 Pheochromocytoma and neuroblastoma statistics.

\begin{tabular}{|c|c|c|}
\hline & Neuroblastoma & Pheochromocytoma \\
\hline Annual incidence (per million) ${ }^{*}$ & 10.4 & $3-8$ \\
\hline Hereditary contribution (\%) & 1 & $>20$ \\
\hline Average age at diagnosis (year) & 1.4 & 42 \\
\hline Mortality due to malignancy $(\%)^{\dagger}$ & 35 & $15-26$ \\
\hline \multicolumn{3}{|c|}{ US extramural federally funded projects ${ }^{\S}$} \\
\hline 2003 Total grants & 34 & 4 \\
\hline 2003 New grants & 11 & 0 \\
\hline 2004 Total grants & 28 & 2 \\
\hline 2004 New grants & 6 & 0 \\
\hline \multicolumn{3}{|c|}{$\begin{array}{l}\text { *The annual incidence of pheochromocytoma is not precisely known, but the high prevalence }(0.05 \%) \text { of pheochromocytomas found } \\
\text { in autopsy series (McNeil et al. 2000) indicates that the tumor is under-diagnosed and that the annual incidence is likely to be higher } \\
\text { than indicated. }\end{array}$} \\
\hline \multicolumn{3}{|c|}{$\begin{array}{l}\text { Malignancy in pheochromocytoma is almost always fatal so the statistics for this tumor represent the prevalence of malignancy in } \\
\text { pheochromocytoma, which is not precisely known. In neuroblastoma, survival varies depending on whether tumors are low risk } \\
\text { (98\% survival in } 35 \% \text { of tumors), intermediate risk (90-95\% survival in } 15 \% \text { of tumors), or high risk (30-40\% survival in } 50 \% \text { of } \\
\text { tumors). }\end{array}$} \\
\hline \multicolumn{3}{|c|}{$\begin{array}{l}\text { \$Numbers of US federally funded projects involving research on pheochromocytoma and neuroblastoma were determined from a } \\
\text { search of the CRISP database (http://crisp.cit.nih.gov/) using the search terms 'pheochromocytoma' or 'neuroblastoma' in both the } \\
\text { project title and the abstract. NIH intramural projects are excluded. }\end{array}$} \\
\hline
\end{tabular}


the most common and often devastating solid tumors of childhood and which, in contrast to pheochromocytoma, receives some funding (Table 1). In neuroblastoma, as in pheochromocytoma, there are aggressive and relatively benign forms of the tumor. As in pheochromocytoma, these different forms of neuroblastoma are not easily diagnosed or distinguished at an early stage when medical intervention would be most beneficial. Investigators working on neuroblastoma and pheochromocytoma were therefore brought together at the Banbury workshop. Apart from serving as a model for future concerted studies about pheochromocytoma, interactions between investigators in the two fields might yield insights into possible common treatments and pathways responsible for differences in aggressive behavior of both types of tumors. This report provides an update on the current status of research on malignant pheochromocytoma as presented by various participants at the meeting. Also outlined are some considerations, directions, and goals for future studies of benign and malignant pheochromocytoma.

\section{Current therapy}

Metastatic disease in pheochromocytoma may be present at the time of initial diagnosis or may only become evident after surgical removal of the primary tumor, usually within 5 years, but sometimes 16 or more years later (Baba et al. 1985, Tanaka et al. 1993, Lenders et al. 2002). Because there is currently no effective cure for malignant pheochromocytoma, most treatments are palliative, but in some cases may reduce tumor burden and prolong survival. Without treatment the 5-year survival is generally less than 50\% (John et al. 1999). The course, however, can be highly variable with occasional patients living more than 20 years after diagnosis (van den Broek \& de Graeff 1978, Yoshida et al. 2001).

As reviewed at the Banbury workshop by William Young, once malignancy is diagnosed, therapy is generally directed at controlling blood pressure, but may also include tumor debulking. Hypertension and catecholamine-dependent symptoms can be controlled with $\alpha$ adrenergic receptor blockade followed by $\beta$-adrenergic receptor blockade. Levels of circulating norepinephrine in patients with extensive disease can be extraordinarily high. In such patients consideration should be given to the potentially cytotoxic effects of catecholamines on the myocardium. Inhibition of catecholamine synthesis with $\alpha$-methyl-paratyrosine (Demser) in exceptional circumstances may be useful in patients with high circulating levels of catecholamines (Decoulx et al. 1987, Lehnert et al. 2004). The significant side-effect profile of $\alpha$-methylparatyrosine, however, limits the dosage and duration of therapy.
Surgery for malignant pheochromocytoma is rarely curative, but resection of a primary mass or metastases can reduce exposure of the cardiovascular system and organs to toxic levels of circulating catecholamines (Mishra et al. 2000). Surgery may also be appropriate for lesions present in life-threatening or debilitating anatomical locations (Nonaka et al. 2000). Surgical debulking may also be used before radio- or chemotherapy, but whether this offers any true benefits has not been assessed by any randomized prospective trial. Alternatives to surgical resection include external beam radiation, cryoablation, radiofrequency ablation, transcatheter arterial embolization, chemotherapy, and radiopharmaceutical therapy (Takahashi et al. 1999, Pacak et al. 2001). Chemotherapy with a combination of cyclophosphamide (Cytoxan), vincristine (Oncovin), and dacarbazine (DTIC-Dome) provides partial remission and improvement of symptoms in up to $50 \%$ of patients with malignant pheochromocytoma (Averbuch et al. 1988). Usually, however, improvement only lasts for 1 to 2 years. Radiopharmaceutical therapy, using high doses of ${ }^{131}$ I-meta-iodobenzylguanidine $\left({ }^{131} \mathrm{I}-\mathrm{MIBG}\right)$, which is transported into the cell via the cell membrane norepinephrine transporter present on most neoplastic chromaffin cells, provides an alternative palliative therapy that can also be effective in temporarily reducing tumor burden and symptoms.

As discussed at the Banbury workshop by Barry Shulkin, therapeutically intended doses of ${ }^{131}$ I-MIBG have some efficacy in treating malignant pheochromocytoma. Small numbers of patients have been treated using widely varying protocols (Krempf et al. 1991, Shapiro et al. 1991, Troncone et al. 1991, Loh et al. 1997, Rose et al. 2003, Safford et al. 2003). Overall, about $75 \%$ of patients treated with ${ }^{131} \mathrm{I}-\mathrm{MIBG}$ show improvement in symptoms, $50 \%$ have reductions in hormonal activity, and $22 \%$ show objective tumor responses. Complete remissions are rare, and progressive disease following ${ }^{131}$ I-MIBG treatment is common (Schlumberger et al. 1992). As a single agent, ${ }^{131} \mathrm{I}-\mathrm{MIBG}$ has limited efficacy in treating malignant pheochromocytoma. Its use in combination with other cytotoxic agents, as is currently being studied in patients with neuroblastoma, may result in additional benefit (Sisson et al. 1999).

\section{Molecular genetics}

Advances in molecular genetics continue to underscore the importance of hereditary factors in the development of pheochromocytoma and propensity to malignancy. Although most cases of pheochromocytoma are sporadic, a significant proportion occur secondary to several hereditary syndromes (Table 2): von Hippel-Lindau (VHL) disease due to mutations of the VHL gene, 
Table 2 Hereditary pheochromocytoma: facts and figures.

\begin{tabular}{lllllc}
\hline & \multicolumn{4}{c}{ Gene } \\
\cline { 2 - 6 } & VHL & RET & NF1 & SDHD & SDHB \\
\hline Frequency in 'sporadic' tumors (\%)* & $6-10$ & $1-5$ & unknown & $2-8$ & $4-9$ \\
Predisposition to malignancy (\%) & 3 & $<3$ & 11 & $<2$ & $66-83$ \\
Tumor catecholamine phenotype & NE & E & E & unknown & unknown \\
Adrenal disease & ++ & ++ & ++ & + & + \\
Extra-adrenal disease & + & - & + & ++ \\
\hline
\end{tabular}

*Frequencies of germ-line mutations in apparently sporadic pheochromocytoma and predispositions to malignancy are derived from several sources of data (Walther et al. 1999; Aguiar et al. 2001; Neumann et al. 2002; Bryant et al. 2003; Bauters et al. 2003; Gimenez-Roqueplo et al. 2003).

'Tumor catecholamine phenotypes are designated as either epinephrine-producing $(E)$ or predominantly norepinephrine-producing (NE).

$++;+;-$, Relative likelihoods of adrenal or extra-adrenal disease from high to low.

multiple endocrine neoplasia type 2A and 2B (MEN 2) due to germline mutations of the RET gene, neurofibromatosis type 1 (NF1) due to mutations of the $N F$ gene, and familial paraganglioma and/or pheochromocytoma syndromes caused by mutations of genes for members of the succinate dehydrogenase family $(S D H B, S D H C$, and SDHD) (Bryant et al. 2003). As genetic screening has become more widely employed, the proportion of cases of pheochromocytoma due to the above mutations has increased above the commonly reported $10 \%$ value. Recently, Neumann et al. (2002) reported in a population-based study that $24 \%$ of apparently sporadic pheochromocytoma patients have such germline mutations, most frequently in VHL $(10 \%)$ and nearly equally frequently (each 5\%) in $R E T, S D H B$ and $S D H D$ genes. Similarly, from a review of hospital-based studies, Bryant et al. (2003) reported that more than $20 \%$ of cases of apparently sporadic pheochromocytoma are associated with one of the above four mutations.

As discussed at the workshop by Patricia Dahia, there remain some familial pheochromocytoma syndromes for which the primary genetic defect is still unknown. Also, the genetic basis of the majority of sporadic pheochromocytomas remains largely uncharacterized. Somatic mutations in the genes involved in hereditary pheochromocytoma occur only infrequently in sporadic tumors (Hofstra et al. 1996, Brauch et al. 1997). By genome-wide scan analysis it now appears that a novel locus in chromosome 2 might account for some remaining cases of familial pheochromocytoma. From a preliminary pilot series of tumors, somatic mutations at this same locus may also be responsible for a significant number of cases of sporadic pheochromocytoma.

Propensity for malignancy in hereditary pheochromocytoma syndromes is highly variable (Table 2). In multiple endocrine neoplasia type $2 \mathrm{~A}$, where pheochromocytomas almost always have an adrenal location, progression to malignancy is rare (Chevinsky et al. 1990). In contrast, in familial paraganglioma/pheochromocytoma syndromes due to mutations of the $S D H B$ gene, there appears to be a greater risk of extra-adrenal tumors and malignancy (Gimenez-Roqueplo et al. 2003). Extra-adrenal tumors also occur in carriers of $V H L$ gene mutations and are frequent in those with SDHD mutations. However, in these groups the risk of malignancy is low. Comparisons of the molecular pathways activated in these and other hereditary pheochromocytoma syndromes, which involve differences in malignant potential, should therefore prove useful in understanding the crucial pathways leading to malignancy.

As presented by Graeme Eisenhofer, comparisons of gene expression profiles in MEN 2A and VHL-associated pheochromocytomas revealed activation of hypoxiadriven angiogenic pathways in VHL tumors. This included increased expression of many genes that have been shown in other studies to be over-expressed in malignant compared with benign pheochromocytomas (Salmenkivi et al. 2001a,b, Favier et al. 2002, Khorram-Manesh et al. 2002, Salmenkivi et al. 2003). Despite this, pheochromocytomas in VHL syndrome have a low rate $(\sim 3 \%)$ of malignancy. The commonalities of gene expression in malignant and VHL-associated pheochromocytomas appear instead to reflect the biochemical phenotype common to these tumors. Malignant and VHL-associated pheochromocytomas produce predominantly norepinephrine and usually have an exclusively noradrenergic biochemical phenotype, whereas MEN 2 tumors produce both epinephrine and norepinephrine (Rao et al. 2000, Eisenhofer et al. 2001, van der Harst et al. 2002). Sporadic, VHL, and malignant pheochromocytomas with a noradrenergic phenotype all show increased expression of the gene for endothelial Per-Arylhydrocarbon receptor nuclear translocator-Sim (PAS) domain protein 1 (Hif-2 $\alpha$ ) compared with benign hereditary and sporadic tumors that 
produce epinephrine (G Eisenhofer et al. 2004). Extraadrenal pheochromocytomas (paragangliomas) also usually produce exclusively norepinephrine and tend to be more aggressive and likely to metastasize than tumors arising in the adrenal glands which more often produce epinephrine (Brown et al. 1972, Kimura et al. 1984, John et al. 1999, van der Harst et al. 2002, Edstrom Elder et al. 2003).

As presented by Ronald de Krijger, differences in genetic profile between benign and malignant pheochromocytomas can be observed by comparative genomic hybridization (Dannenberg et al. 2000). This genome-wide analysis technique compares normal and tumor DNA by hybridization of differentially labeled DNA to normal human chromosomes and computer-aided analysis of over- or under-representation of either fluorochrome. In this way, it was shown that several regions of loss (8p, $18 p)$ and gain $(5 p, 7 p, 12 q)$ occurred significantly more often in malignant than in benign pheochromocytomas. The main drawback of comparative genomic hybridization, the relatively low resolution, will be overcome by the advent of genome-wide and chromosome arm-specific DNA microarrays, which offer much higher resolution and can pinpoint chromosomal areas of interest for further detailed studies.

The aforementioned differences in tumor genotype and phenotype in benign and malignant pheochromocytomas indicate the importance of considering tumor location, genetics, and biochemical characteristics in proteomics or DNA microarray studies of molecular pathways responsible for malignancy. Comparisons of malignant versus benign pheochromocytomas should therefore include well-defined subgroups of hereditary and sporadic norepinephrine- and epinephrine-producing tumors, and adrenal and extra-adrenal paragangliomas. In studies that involve extra-adrenal paragangliomas, appropriate reporting of anatomic location and other factors, as outlined elsewhere, is essential (Lack et al. 2003). Attempts to distinguish paragangliomas associated with sympatho-chromaffin tissue, that produce catecholamines, from those associated with parasympathetic tissue, that do not produce significant amounts of catecholamines, would also be useful.

As outlined at the workshop by David Smith, studies employing proteomics or DNA microarray technology require large numbers of well-characterized tumor samples and access to all relevant clinical data so that appropriate groupings and comparisons can be made. Associated additional technologies such as comparative genomic hybridization can be useful for tracking revealed pathways to candidate genes responsible for tumorigenesis and malignancy. For a rare disease such as pheochromocytoma, such studies are probably best undertaken on a multicenter basis with stringent guidelines for consistent and comprehensive clinical data collection, tissue procurement, tumor banking, and analysis and follow-up of data and patients.

\section{Diagnostic and prognostic markers}

As emphasized throughout the workshop, the pathologic distinction of benign and malignant pheochromocytomas and extra-adrenal paragangliomas remains a diagnostic challenge. Nevertheless, as reviewed by Arthur Tischler, several studies have attempted to distinguish benign from malignant pheochromocytoma using histopathological classifications that incorporate retrospective assessment of growth characteristics, cellularity, vascular invasion, capsular invasion, mitotic figures, necrosis and other variables (Kimura \& Sasano 1990, Linnoila et al. 1990, van der Harst et al. 2000, Thompson 2002). Such grading systems require assessment of many variables and as yet have not been applied prospectively for diagnostic or prognostic purposes.

Hendrik Lehnert presented evidence that molecular markers, such as expression of human telomerase reverse transcriptase and heat shock protein 90 (HSP90) (Boltze et al. 2003, Elder et al. 2003), might provide alternative methods for distinguishing malignant from benign pheochromocytoma (Table 3). Other possible molecular markers include secretogranin II-derived peptide (Yon et al. 2003) and numerous factors associated with angiogenesis (Salmenkivi et al. 2001a,b, Favier et al. 2002, Khorram-Manesh et al. 2002, Zielke et al. 2002, Salmenkivi et al. 2003). Thomas Giordano indicated that a truly reliable predictor of malignant behavior would likely only be achieved through use of a combination of molecular markers. The availability of a transcriptional signature for malignant pheochromocytoma and paraganglioma derived from gene expression profiling studies might permit development of diagnostic tests for this purpose (Giordano 2003). The consensus of the meeting participants was that transcriptional profiling, at least in the short-term, should be compared with and probably integrated with histopathological criteria proposed in the earlier studies. Carefully designed prospective studies will be required to provide convincing documentation of the reliability of these tests. Assessment of the prognostic value of such tests requires careful patient follow-up over many years.

Apart from assessment of tumor tissue samples, there also exists the possibility to establish malignancy or potential for malignancy from markers in biological fluids. As reviewed by David Goldstein, high plasma and urinary levels of dihydroxyphenylalanine and dopamine, the immediate precursors of norepinephrine, are biochemical 
Table 3 Molecular markers of malignant pheochromocytoma.

\begin{tabular}{ll}
\hline & Reference \\
\hline Heat shock protein 90 & Boltze et al. (2003) \\
Human telomerase reverse transcriptase & Boltze et al. (2003), Elder et al. (2003) \\
Vascular endothelial growth factor & Favier et al. (2002), Zielke et al. (2002), Salmenkivi et al. (2003) \\
Vascular endothelial growth factor receptor 2 & Favier et al. (2002) \\
Hypoxia inducible factor 2-alpha & Favier et al. (2002) \\
Cyclooxygenase-2 & Salmenkivi et al. (2001b) \\
Tenascin C & Salmenkivi et al. (2001a) \\
N-cadherin & Khorram-Manesh et al. (2002) \\
Secretogranin II-derived peptide EM66 & Yon et al. (2003) \\
\hline
\end{tabular}

hallmarks that may characterize malignant pheochromocytoma (Anton et al. 1967, Goldstein et al. 1986, John et al. 1999, Januszewicz et al. 2001, van der Harst et al. 2002). While suggestive of a dedifferentiated state that might be associated with malignancy, these markers do not, however, accurately discriminate benign from malignant pheochromocytomas. Karel Pacak presented data, based on a proteomics study, indicating that the patterns of expression of peptides and proteins in serum could distinguish patients with solitary apparently benign pheochromocytomas from those with metastases. An accurate diagnostic test based on such patterns would represent a major advance in guiding patient management.

Currently, identification of metastases requires imaging studies, such as whole body computed tomography (CT) or magnetic resonance imaging (MRI) scans, ${ }^{131} \mathrm{I}-$ metaiodobenzylguanidine ( $\left.{ }^{131} \mathrm{I}-\mathrm{MIBG}\right)$ scintigraphy, ${ }^{131} \mathrm{I}$ MIBG single photon emission computed tomography (SPECT), and bone scans (Shapiro et al. 2001). Other nuclear imaging technologies such as ${ }^{18} \mathrm{~F}$-fluorodeoxyglucose positron emission tomography (PET) (Neumann et al. 1996) and ${ }^{111}$ In-octreotide SPECT (Tenenbaum et al. 1995, van der Harst et al. 2001) are also available, but do not have the same level of sensitivity and specificity as imaging agents such as MIBG that target the cell membrane norepinephrine transporter present on most pheochromocytomas. MIBG imaging, however, only detects $85-90 \%$ of pheochromocytomas and sensitivity may be lower for malignant pheochromocytoma. Recently Ilias et al. (2003) reported that 7 out of 16 patients with malignant pheochromocytoma had negative ${ }^{131}$ I-MIBG scans indicating a sensitivity of $56 \%$. Use of PET scanning with the imaging agent, ${ }^{18} \mathrm{~F}$-6-fluorodopamine, which also targets the norepinephrine transporter, provided a more sensitive method for identifying metastatic pheochromocytoma. Presently, however, the technology has limited availability and, as in MIBG imaging, still fails to detect occasional dedifferentiated tumors that lack expression or express low levels of the norepinephrine transporter. In such patients ${ }^{18} \mathrm{~F}$-fluorodeoxyglucose or ${ }^{111}$ In-octreotide can be useful (Tenenbaum et al. 1995).
PET scanning with ${ }^{18}$ F-fluorodopa provides another alternative that in preliminary studies has yielded encouraging results (Hoegerle et al. 2002).

Another problem associated with present day diagnosis and treatment of malignant pheochromocytoma is a lack of consensus about when imaging studies should be carried out to detect or exclude metastatic disease. Although by no means unanimous, the view supported by most of the participants at the workshop was that malignant disease should be considered at the time of initial diagnosis and before surgical resection. This contrasts with a recent report suggesting that the routine use of MIBG scintigraphy in the uncomplicated patient before operation may be unnecessary (Miskulin et al. 2003). When there is increased risk for malignant disease (e.g. paraganglioma or $>6 \mathrm{~cm}$ in diameter adrenal pheochromocytoma) or increased risk for more than one catecholamine-secreting tumor (e.g. paraganglioma patients), MIBG imaging should always be considered preoperatively. Whether or not MIBG imaging is used routinely, it must also be considered that the modality has imperfect sensitivity for excluding all cases of malignancy. Thus, biochemical testing should always be repeated after recovery from surgical resection of a primary mass to exclude any remaining disease or metastases.

Because metastases may be microscopic at the time of initial surgery, and therefore may not present as malignant disease until many years later, biochemical screening should continue at yearly intervals (Baba et al. 1985, Tanaka et al. 1993, Lenders et al. 2002). Again, however, there is a lack of consensus regarding the duration of follow-up and in what form follow-up screening should take. Some have indicated that biochemical testing alone is insufficient and that follow-up examinations should include imaging studies (Morikawa et al. 2001). Although it is generally agreed that follow-up should be long-term, it has recently been suggested that follow-up may not be necessary for all patients with a resected solitary tumor (Edstrom Elder et al. 2003). Certainly the accumulating evidence indicates that continued screening may be most important in patients with 
paragangliomas or tumors judged by existing histopathological criteria to be at risk for malignancy.

The above issues for patient management will depend on further advances in diagnosis and treatment. With improved diagnostic markers it should become possible to assess more effectively the presence of malignancy. With improved prognostic markers it should also become possible to ascertain whether a tumor is truly pathologically benign and does not require follow-up, or possesses malignant potential and requires regular patient monitoring. With this and further developments in treatment it may even be possible to target patients at risk for malignancy with prophylactic therapies. Certainly, as more effective treatments are developed it should become possible to establish a consensus about the importance of an earlier diagnosis of malignant disease, when therapies might be more likely to be curative.

\section{Model systems}

As discussed at the Banbury workshop by Arthur Tischler, model systems are essential for the determination of mechanisms and pathways responsible for tumorigenesis and malignancy in pheochromocytoma and for the development and testing of new treatments. A problem here is lack of an established human pheochromocytoma cell line. Currently, the only relevant cell lines are those from pheochromocytomas in rodents. These lines have been difficult to establish because pheochromocytoma cells usually cease proliferating in cell culture. Current models include the rat PC12 line, established in 1976 (Greene \& Tischler 1976), and several more recently developed mouse pheochromocytoma ('MPC') lines from neurofibromatosis knockout mice (Powers et al. 2000). Advantages of the PC12 line include an enormous amount of accrued data and a remarkably stable phenotype for 28 years. A disadvantage is that the PC12 line is representative of only a single cell from one tumor. In contrast, multiple MPC lines with somewhat differing characteristics have been derived from separate tumors. These lines all over-express non-mutated ret, similar to many human pheochromocytomas, making them highly relevant for studies of ret signaling (Powers et al. 2002).

There also exist several animal models of pheochromocytoma. In rats, numerous pharmacologically diverse and usually non-mutagenic substances readily induce pheochromocytomas. Some agents that cause rat pheochromocytomas in long-term toxicity studies (e.g. the anti-hypertensive drug, reserpine) can be shown to increase chromaffin cell proliferation in short-term experiments. Tischler and colleagues hypothesize that chromaffin cell mitogenesis may set the stage for genetic damage by endogenous mutagens produced during catecholamine metabolism. Potential mutagens include quinones, semiquinones, reactive oxygen species, and short-lived aldehyde intermediates produced by oxidative deamination of catecholamines. Some disadvantages of the rat model are that the genetic basis of pheochromocytomas in that species and relevance to human disease are unknown.

In contrast to rats, pheochromocytomas in mice arise with increased frequency in several transgenic or knockout models involving genes associated with human pheochromocytomas. These include the neurofibromatosis knockouts described above and MEN 2B transgenic models (Smith-Hicks et al. 2000). In addition to the germline abnormalities, common denominators between human and mouse pheochromocytomas include similar profiles of secondary genetic changes detected by comparative genomic hybridization. These include deletions of mouse chromosome 4 that are homologous to the common human 1p deletion (Benn et al. 2000, You et al. 2002), and deletions of mouse chromosomes 4 and 9 that are homologous to human $3 p$ and $3 q$ deletions ( $\mathrm{J} \mathrm{F}$ Powers, A S Tischler, M Mohammed \& R Naeem, unpublished observations). Disruptions of the gene for phosphatase and tension homologue deleted on chromosome 10 (PTEN), a tumor suppressor located on mouse chromosome 4, appear in particular to predispose to spontaneous development of pheochromocytomas and may represent a candidate for human disease (Podsypanina et al. 2001, You et al. 2002).

The use of nude mice to host pheochromocytoma cells from human tumors and animal cell lines, provides another model that may be particularly useful in assessing the efficacy of new treatments (Zielke et al. 1998). Using this model, antibodies to vascular endothelial growth factor have been shown to inhibit angiogenesis in PC12 xenografts (Zielke et al. 2002). In another study, halofuginone, an inhibitor of collagen synthesis and extracellular matrix deposition, was found to markedly reduce tumor size in xenografts of human VHL pheochromocytomas (Gross et al. 2003). Since PC12 and MPC cell lines were developed using xenografts, this system may also be the most promising for development of muchneeded human pheochromocytoma cell lines.

\section{Future therapies and new initiatives}

Reports of occasional patients who show apparent complete remission of malignant disease after ${ }^{131} \mathrm{I}-$ MIBG therapy (Rose et al. 2003) provide an incentive for continued studies that seek to improve targeting of this radiopharmaceutical to pheochromocytoma cells (Fig. 1). Similarly, objective response rates to 

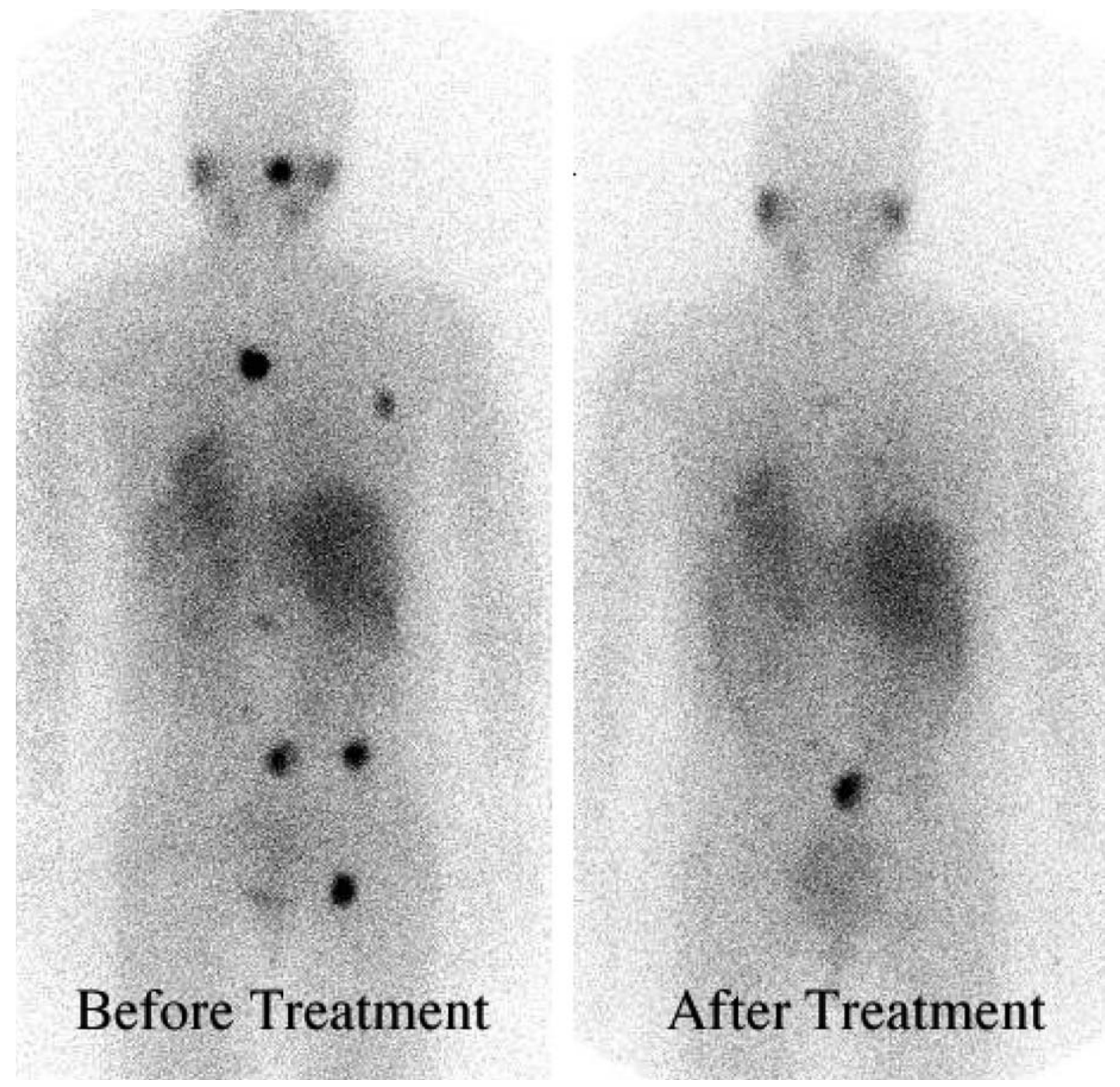

Figure $1{ }^{131}$ I-MIBG scintigraphs of a patient with malignant pheochromocytoma before and after high-dose MIBG treatment based on the protocol of Rose et al. (2003). Images kindly provided by the Department of Nuclear Medicine, University of Düsseldorf.

${ }^{131}$ I-MIBG therapy in heavily pretreated neuroblastoma patients may be as high as 30-50\% (Matthay et al. 1998, Kang et al. 2003), and this is superior to essentially every other novel agent studied in the setting of a relapsed highrisk tumor. Ongoing investigations have been designed to combine ${ }^{131}$ I-MIBG with conventional chemotherapy, and/or to increase the dose intensity of ${ }^{131}$ I-MIBG by providing for multiple infusions. This has been an extremely well-tolerated therapy with hematopoietic toxicity being dose limiting, but abrogated with peripheral blood stem cell support (Matthay et al. 1998, Kang et al. 2003).
Accumulation and retention of ${ }^{131}$ I-MIBG in pheochromocytoma tumor cells depends on expression of catecholamine transporters on the cell surface and in chromaffin granules within which catecholamines are stored (Jaques et al. 1987, Kolby et al. 2003). Thus, better and more toxic substrates for these transporters or strategies designed to increase the expression of transporter systems on tumor cells before ${ }^{131} \mathrm{I}-\mathrm{MIBG}$ therapy offer approaches to improve therapeutic targeting. Such approaches, which to date have been mainly limited to experimental model systems, include norepinephrine transporter gene transfer (Cunningham et al. 2000, 
Boyd et al. 2001) and increasing expression of the norepinephrine transporter using cisplatin (Armour et al. 1997) and combinations of interferon-gamma, tumor necrosis factor-alpha, and retinoic acid (Montaldo et al. 1996). A clinical treatment protocol, based on such studies, has been approved at the NIH, Bethesda, MD, USA, but has been on hold due to institutional funding and staffing limitations. At the Children's Hospital of Philadelphia, John Maris reports similar problems for their clinical trials to treat neuroblastoma, which together with high costs and lack of appropriate commercial sources of ${ }^{131}$ I-MIBG constrains availability of the therapy to only a few of many eligible pediatric patients. Future progress in these and other clinical therapeutics trials requires encouragement of a multidisciplinary team approach at the institutional level with an adequate level of support to ensure that all eligible patients have access to new experimental treatments as these become available. Identification of a suitable vendor at the US national level would be useful for trials involving ${ }^{131} \mathrm{I}-\mathrm{MIBG}$.

Because neuroendocrine tumors, including pheochromocytomas, express a number of subtypes of somatostatin receptors, administration of analogs of somatostatin have been proposed as another treatment for malignant pheochromocytoma (Wiseman \& Kvols 1995). Although some initial small scale studies have indicated reduction in tumor catecholamine production (Invitti et al. 1993) or symptomatic improvement (Kopf et al. 1997), this has not been confirmed by other groups (Lamarre-Cliche et al. 2002) and may only be useful in subgroups of tumors with membrane-associated somatostatin type 3 receptors (Mundschenk et al. 2003). Nevertheless, as discussed at the workshop by Hendrik Lehnert, combined treatment with novel somatostatin analogs and ${ }^{131}$ I-MIBG may confer additional benefit over ${ }^{131}$ I-MIBG treatment alone.

Development of other more effective targeted therapies for malignant pheochromocytoma can be expected to take advantage of the wealth of new drugs being developed in response to advances in the elucidation of pathways responsible for other cancers. Use of DNA microarray and proteomics technologies for understanding the pathways contributing to benign and malignant pheochromocytoma should be useful for guiding the choice of the most appropriate of these agents for future therapeutic trials.

Already there are suggestions of possible targets in malignant pheochromocytoma for new classes of anticancer drugs being developed in response to improved understanding of pathways involved in other malignancies (Table 3). Over-expression of HSP90 in malignant pheochromocytomas (Boltze et al. 2003), in particular, indicates one promising therapeutic target for a new class of anticancer drugs being developed to inhibit this protein
(Maloney \& Workman 2002). HSP90 is now understood to function as a molecular chaperone that maintains the folding and conformation of proteins crucial in regulating the balance between degradation and synthesis of cell signaling proteins, including many involved in multiple oncogenic pathways. Such proteins include the human telomerase reverse transcriptase, which also shows increased expression in malignant pheochromocytoma (Boltze et al. 2003, Elder et al. 2003). Should HSP90 be proven to be involved in the transition from a benign to malignant pheochromocytoma phenotype, then new inhibitors of the protein, such as 17-allylamino, 17-demethoxygeldamycin (Sausville et al. 2003), may be of value as treatments for the malignancy. Findings from several groups that malignant pheochromocytomas are characterized by increased expression of factors associated with angiogenesis (Table 3) suggest other pathways that may respond to new anti-angiogenic drugs currently in development or approved by the Food and Drug Administration for specific types of cancer.

Even with the advent of new therapeutic targets and drugs it remains likely that a combination of therapies will be required for effective treatment. Given the heterogenous nature of pheochromocytomas, it is also likely that for best therapeutic results, treatments may have to be tailored according to differences in underlying pathways. Developing such approaches will benefit from the opportunities available from the new genomic and proteomic methodologies and other developments associated with new drug discovery technologies, such as high throughput screening of drug candidates.

The current unfolding of the NIH roadmap (Zerhouni 2003) makes this a time of flux in research priorities and a movement towards future advances in medical research that will take advantage of the tremendous information available in the post-genome era. This is also a pivotal time-point to move forward from past and present methods and procedures for diagnosis, localization, and treatment of pheochromocytoma to research into novel methodologies based on the new pathways to discovery (Table 4). As outlined in the new roadmap, taking advantage of the new technologies available in the postgenome era is best undertaken by multidisciplinary research teams involving centers and individuals with the necessary expertise. Importantly, research about pheochromocytoma already includes such a platform, involving interactions among clinicians and investigators in diverse fields, including endocrinology, human genetics, clinical chemistry, radiology, nuclear medicine, surgery, pathology, and oncology. This already existing multidisciplinary platform can be broadened to further take advantage of new technologies and, due to the rare nature of the tumor, should also better bring together various 
Table 4 Malignant pheochromocytoma - past, present, and future

\begin{tabular}{|c|c|c|c|}
\hline & Past & Present & Future \\
\hline Biochemical diagnosis & $\begin{array}{l}\text { Urinary VMA, catecholamines, } \\
\text { and total metanephrines. } \\
\text { Plasma catecholamines }\end{array}$ & $\begin{array}{l}\text { Plasma and urinary fractionated } \\
\text { metanephrines and catecholamines }\end{array}$ & $\begin{array}{l}\text { Plasma markers derived } \\
\text { from proteomics and RNA } \\
\text { technology }\end{array}$ \\
\hline Tumor localization & X-ray & CT, MRI, MIBG, bone scans & $\begin{array}{l}\text { Functional and molecular } \\
\text { imaging with PET }\end{array}$ \\
\hline Pathological diagnosis & Chromaffin reaction & $\begin{array}{l}\text { Histopathological markers, } \\
\text { presence of metastases }\end{array}$ & $\begin{array}{l}\text { DNA microarrays and } \\
\text { molecular markers }\end{array}$ \\
\hline Genetic predisposition & Family history & Mutation analysis & $\begin{array}{l}\text { High-throughput } \\
\text { sequencing, microarray-based } \\
\text { genotyping }\end{array}$ \\
\hline $\begin{array}{l}\text { Post-surgical testing } \\
\text { and management }\end{array}$ & $\begin{array}{l}\text { Biochemical testing 2-6 } \\
\text { weeks post-surgery }\end{array}$ & $\begin{array}{l}\text { Biochemical testing } 2-6 \\
\text { weeks post-surgery. } \\
\text { Annual screening of all patients }\end{array}$ & $\begin{array}{l}\text { Biochemical testing } 2-6 \text { weeks } \\
\text { post-surgery. Annual screening } \\
\text { of selected patients based on } \\
\text { prognostic molecular markers, } \\
\text { prophylactic therapies in select } \\
\text { patients }\end{array}$ \\
\hline Therapy & $\begin{array}{l}\text { Adrenergic blockers, } \\
\alpha \text {-methyl-paratyrosine and } \\
\text { use of other drugs for } \\
\text { symptomatic relief }\end{array}$ & $\begin{array}{l}\text { Surgical debulking, chemotherapy, } \\
{ }_{131} \text { I-MIBG radiotherapy, } \\
\text { radiofrequency ablation, cryoablation, } \\
\text { chemoembolization }\end{array}$ & $\begin{array}{l}\text { Tumor sensitization to } \\
{ }^{131} \text { I-MIBG radiotherapy, } \\
\text { pathway-specific molecular } \\
\text { targeting, cancer vaccines, } \\
\text { gene therapy }\end{array}$ \\
\hline
\end{tabular}

VMA, vanillyImandelic acid.

groups of investigators involved in pheochromocytoma research. This will be particularly important as new treatments and drugs become available.

Rather than the fragmented approach typical of previous trials, such as those that have assessed the therapeutic efficacy of ${ }^{131} \mathrm{I}-\mathrm{MIBG}$, it is desirable for future trials of novel targeted therapies for malignant pheochromocytoma to be carried out in a more concerted and coordinated manner. The support and establishment through the NIH roadmap of new centers for bioinformatics, computational biology, database libraries and other tools provides added incentive for investigators working on pheochromocytoma to pull together for a more focused and concerted approach to find solutions to the outstanding problems associated with this tumor.

The Pheochromocytoma RESearch Support ORganization (PRESSOR) was established as an outcome of the November 2003 workshop at Cold Spring Harbor to facilitate improved evidence-based multidisciplinary approaches for research on pheochromocytoma. The consortium (http://www.pressor.org) has over 100 members worldwide, including many leaders in established fields as well as in new or emerging fields of research. One of the goals of the consortium is to develop and implement effective treatments for malignant pheochromocytoma. Another goal is to establish new diagnostic and prognostic tests for discriminating benign from malignant and other forms of pheochromocytoma. The consortium also seeks to create platforms for the exchange of information on pheochromocytoma research among investigators, physicians, and patients. It will also support, through evidencebased studies, the establishment of consensus-derived guidelines for effective biochemical diagnosis, localization, management, and treatment of benign, malignant, and other forms of pheochromocytoma. Through a focused and coordinated approach, we envisage that members of the consortium will be able to satisfy these goals more rapidly than would otherwise be possible.

\section{References}

Aguiar RC, Cox G, Pomeroy SL \& Dahia PL 2001 Analysis of the SDHD gene, the susceptibility gene for familial paraganglioma syndrome (PGL 1), in pheochromocytomas. Journal of Clinical Endocrinology and Metabolism 86 2890-2894.

Anton AH, Greer M, Sayre DF \& Williams CM 1967 Dihydroxyphenylalanine secretion in a malignant pheochromocytoma. American Journal of Medicine $\mathbf{4 2}$ 469-475.

Armour A, Cunningham SH, Gaze MN, Wheldon TE \& Mairs RJ 1997 The effect of cisplatin pretreatment on the accumulation of MIBG by neuroblastoma cells in vitro. British Journal of Cancer $\mathbf{7 5}$ 470-476.

Averbuch SD, Steakley CS, Young RC, Gelmann EP, Goldstein DS, Stull R \& Keiser HR 1988 Malignant pheochromocytoma: effective treatment with a combination 
of cyclophosphamide, vincristine and dacarbazine. Annals of Internal Medicine 109 267-273.

Baba T, Machida K, Ozaki I, Okushima T, Murabayashi S, Kamata Y, Imamura K \& Takebe K 1985 A malignant pheochromocytoma with ileus, polyuria and hypercalcemia: a case of recurrence 17 years after the initial operation. Endocrinology Japan 32 337-345.

Bauters C, Vantygheum M-C, Leteurtre E, Odou M-F, Mouton C, Porchet N, Wemeau J-L, Proye C \& Pigny P 2003 Hereditary phaeochromocytoma and paragangliomas: a study of five susceptibility genes. Journal of Medical Genetics $\mathbf{4 0}$ e75.

Benn DE, Dwight T, Richardson AL, Delbridge L, Bambach CP, Stowasser M, Gordon RD, Marsh DJ \& Robinson BG 2000 Sporadic and familial pheochromocytomas are associated with loss of at least two discrete intervals on chromosome $1 \mathrm{p}$. Cancer Research 60 7048-7051.

Boltze C, Mundschenk J, Unger N, Schneider-Stock R, Peters B, Mawrin C, Hoang-Vu C, Roessner A \& Lehnert H 2003 Expression profile of the telomeric complex discriminates between benign and malignant pheochromocytoma. Journal of Clinical Endocrinology and Metabolism 88 4280-4286.

Boyd M, Mairs RJ, Mairs SC, Wilson L, Livingstone A, Cunningham SH, Brown MM, Quigg M \& Keith WN 2001 Expression in UVW glioma cells of the noradrenaline transporter gene, driven by the telomerase RNA promoter, induces active uptake of $\left[{ }^{131} \mathrm{I}\right] \mathrm{MIBG}$ and clonogenic cell kill. Oncogene 20 7804-7808.

Brauch H, Hoeppner W, Jahnig H, Wohl T, Engelhardt D, Spelsberg F \& Ritter MM 1997 Sporadic pheochromocytomas are rarely associated with germline mutations in the vhl tumor suppressor gene or the ret protooncogene. Journal of Clinical Endocrinology and Metabolism 82 4101-4104.

van den Broek PJ \& de Graeff J 1978 Prolonged survival in a patient with pulmonary metastases of a malignant pheochromocytoma. Netherlands Journal of Medicine $\mathbf{2 1}$ 245-247.

Brown WJ, Barajas L, Waisman J \& De Quattro V 1972 Ultrastructural and biochemical correlates of adrenal and extra-adrenal pheochromocytoma. Cancer 29 744-759.

Bryant J, Farmer J, Kessler LJ, Townsend RR \& Nathanson KL 2003 Pheochromocytoma: the expanding genetic differential diagnosis. Journal of the National Cancer Institute $\mathbf{9 5}$ 1196-1204.

Chevinsky AH, Minton JP \& Falko JM 1990 Metastatic pheochromocytoma associated with multiple endocrine neoplasia syndrome type II. Archives of Surgery $\mathbf{1 2 5}$ 935-938.

Cunningham S, Boyd M, Brown MM, Carlin S, McCluskey A, Livingstone A, Mairs RJ \& Wheldon TE 2000 A gene therapy approach to enhance the targeted radiotherapy of neuroblastoma. Medical and Pediatric Oncology 35 708-711.

Dannenberg H, Speel EJ, Zhao J, Saremaslani P, van Der Harst E, Roth J, Heitz PU, Bonjer HJ, Dinjens WN, Mooi WJ, Komminoth P \& de Krijger RR 2000 Losses of chromosomes $1 p$ and $3 q$ are early genetic events in the development of sporadic pheochromocytomas. American Journal of Pathology $157353-359$.
Decoulx M, Wemeau JL, Racadot-Leroy N, Grimbert I, Proye C \& Plane C 1987 Alpha-methyl-paratyrosine in the treatment of malignant pheochromocytoma. Reveu Medecine Interne $\mathbf{8}$ 383-388.

Edstrom Elder E, Hjelm Skog AL, Hoog A \& Hamberger B 2003 The management of benign and malignant

pheochromocytoma and abdominal paraganglioma. European Journal of Surgical Oncology 29 278-283.

Eisenhofer G, Walther MM, Huynh TT, Li ST, Bornstein SR, Vortmeyer A, Mannelli M, Goldstein DS, Linehan WM, Lenders JW \& Pacak K 2001 Pheochromocytomas in von Hippel-Lindau syndrome and multiple endocrine neoplasia type 2 display distinct biochemical and clinical phenotypes. Journal of Clinical Endocrinology and Metabolism $\mathbf{8 6}$ 1999-2008.

Eisenhofer G, Huynh T-T, Pacak K, Brouwers FM, Walther MM, Linehan WM, Munson PJ, Mannelli M, Goldstein DS \& Elkahloun AG 2004 Distinct gene expression profiles in norepinephrine and epinephrine producing hereditary and sporadic pheochromocytomas: Activation of hypoxia-driven angiogenic pathways in von Hippel-Lindau syndrome. Endocrine-Related Cancer (In Press).

Elder EE, Xu D, Hoog A, Enberg U, Hou M, Pisa P, Gruber A, Larsson C \& Backdahl M 2003 KI-67 and hTERT expression can aid in the distinction between malignant and benign pheochromocytoma and paraganglioma. Modern Pathology 16 246-255.

Favier J, Plouin PF, Corvol P \& Gasc JM 2002 Angiogenesis and vascular architecture in pheochromocytomas: distinctive traits in malignant tumors. American Journal of Pathology 161 1235-1246.

Gimenez-Roqueplo AP, Favier J, Rustin P, Rieubland C, Crespin M, Nau V, Khau Van Kien P, Corvol P, Plouin PF \& Jeunemaitre X 2003 Mutations in the SDHB gene are associated with extra-adrenal and/or malignant phaeochromocytomas. Cancer Research 63 5615-5621.

Giordano TJ 2003 Gene expression profiling of endocrine tumors using DNA microarrays: progress and promise. Endocrine Pathology 14 107-116.

Goldstein DS, Stull R, Eisenhofer G, Sisson JC, Weder A, Averbuch SD \& Keiser HR 1986 Plasma 3,4dihydroxyphenylalanine (dopa) and catecholamines in neuroblastoma or pheochromocytoma. Annals of Internal Medicine 105 887-888.

Goldstein RE, O'Neill JA Jr, Holcomb GW 3rd, Morgan WM 3rd, Neblett WW 3rd, Oates JA, Brown N, Nadeau J, Smith B, Page DL, Abumrad NN \& Scott HW Jr 1999 Clinical experience over 48 years with pheochromocytoma. Annals of Surgery 229 755-766.

Greene LA \& Tischler AS 1976 Establishment of a noradrenergic clonal line of rat adrenal pheochromocytoma cells which respond to nerve growth factor. PNAS 73 2424-2428.

Gross DJ, Reibstein I, Weiss L, Slavin S, Dafni H, Neeman M, Pines M \& Nagler A 2003 Treatment with halofuginone results in marked growth inhibition of a von Hippel-Lindau pheochromocytoma in vivo. Clinical Cancer Research 9 3788-3793.

van der Harst E, Bruining HA, Jaap Bonjer H, van der Ham F, Dinjens WN, Lamberts SW, de Herder WW, Koper JW, 
Stijnen T, Proye C, Lecomte-Houcke M, Bosman FT \& de Krijger RR 2000 Proliferative index in phaeochromocytomas: does it predict the occurrence of metastases? Journal of Pathology 191 175-180.

van der Harst E, de Herder WW, Bruining HA, Bonjer HJ, de Krijger RR, Lamberts SW, van de Meiracker AH, Boomsma F, Stijnen T, Krenning EP, Bosman FT \& Kwekkeboom DJ $2001\left[{ }^{123}\right.$ I] metaiodobenzylguanidine and $\left[{ }^{111}\right.$ In] octreotide uptake in benign and malignant pheochromocytomas. Journal of Clinical Endocrinology and Metabolism 86 685-693.

van der Harst E, de Herder WW, de Krijger RR, Bruining HA, Bonjer HJ, Lamberts SW, van den Meiracker AH, Stijnen TH \& Boomsma F 2002 The value of plasma markers for the clinical behaviour of phaeochromocytomas. European Journal of Endocrinology 147 85-94.

Hoegerle S, Nitzsche E, Altehoefer C, Ghanem N, Manz T, Brink I, Reincke M, Moser E \& Neumann HP 2002 Pheochromocytomas: detection with 18F DOPA whole body PET - initial results. Radiology 222 507-512.

Hofstra RM, Stelwagen T, Stulp RP, de Jong D, Hulsbeek M, Kamsteeg EJ, van den Berg A, Landsvater RM, Vermey A, Molenaar WM, Lips CJ \& Buys CH 1996 Extensive mutation scanning of RET in sporadic medullary thyroid carcinoma and of RET and VHL in sporadic pheochromocytoma reveals involvement of these genes in only a minority of cases. Journal of Clinical Endocrinology and Metabolism 81 2881-2884.

Ilias I, Yu J, Carrasquillo JA, Chen CC, Eisenhofer G, Whatley M, McElroy B \& Pacak K 2003 Superiority of 6-[18F]fluorodopamine positron emission tomography versus $\left[{ }^{131} \mathrm{I}\right]$ metaiodobenzylguanidine scintigraphy in the localization of metastatic pheochromocytoma. Journal of Clinical Endocrinology and Metabolism 88 4083-4087.

Invitti C, De Martin I, Bolla GB, Pecori Giraldi F, Maestri E, Leonetti G \& Cavagnini F 1993 Effect of octreotide on catecholamine plasma levels in patients with chromaffin cell tumors. Hormone Research 40 156-160.

Januszewicz W, Wocial B, Januszewicz A, Gryglas P \& Prejbisz A 2001 Dopamine and dopa urinary excretion in patients with pheochromocytoma - diagnostic implications. Blood Pressure 10 212-216.

Jaques S Jr, Tobes MC \& Sisson JC 1987 Sodium dependency of uptake of norepinephrine and $\mathrm{m}$-iodobenzylguanidine into cultured human pheochromocytoma cells: evidence for uptake-one. Cancer Research 47 3920-3928.

John H, Ziegler WH, Hauri D \& Jaeger P 1999 Pheochromocytomas: can malignant potential be predicted? Urology 53 679-683.

Kang TI, Brophy P, Hickeson M, Heyman S, Evans AE, Charron M \& Maris JM 2003 Targeted radiotherapy with submyeloablative doses of ${ }^{131} \mathrm{I}$-MIBG is effective for disease palliation in highly refractory neuroblastoma. Journal of Pediatrics and Hematological Oncology 25 769-773.

Khorram-Manesh A, Ahlman H, Jansson S \& Nilsson O 2002 Ncadherin expression in adrenal tumors: upregulation in malignant pheochromocytoma and downregulation in adrenocortical carcinoma. Endocrine Pathology 13 99-110.

Kimura N \& Sasano N 1990 A comparative study between malignant and benign pheochromocytoma using morphometry, cytophotometry, and immunohistochemistry.
In Endocrine Pathology Update, pp 99-117. Eds J Lechago \& T Kameya. New York: Field \& Wood.

Kimura N, Sasano N, Miura Y \& Kobayashi K 1984 Adrenal and extra-adrenal pheochromocytomas: an ultrastructural and formaldehyde-induced fluorescence study with catecholamine content. Tohoku Journal of Experimental Medicine 142 1-14.

Kolby L, Bernhardt P, Levin-Jakobsen AM, Johanson V, Wangberg B, Ahlman H, Forssell-Aronsson E \& Nilsson O 2003 Uptake of meta-iodobenzylguanidine in neuroendocrine tumours is mediated by vesicular monoamine transporters. British Journal of Cancer 89 1383-1388.

Kopf D, Bockisch A, Steinert H, Hahn K, Beyer J, Neumann HP, Hensen J \& Lehnert H 1997 Octreotide scintigraphy and catecholamine response to an octreotide challenge in malignant phaeochromocytoma. Clinical Endocrinology 46 39-44.

Krempf M, Lumbroso J, Mornex R, Brendel AJ, Wemeau JL, Delisle MJ, Aubert B, Carpentier P, Fleury-Goyon MC, Gibold C et al. 1991 Use of $\mathrm{m}-\left[{ }^{131} \mathrm{I}\right]$ iodobenzylguanidine in the treatment of malignant pheochromocytoma. Journal of Clinical Endocrinology and Metabolism 72 455-461.

Lack EE, Lloyd RV, Carney JA \& Woodruff JW 2003 Recommendations for the reporting of extra-adrenal paragangliomas. The Association of Directors of Anatomic and Surgical Pathology. Human Pathology 34 112-113.

Lamarre-Cliche M, Gimenez-Roqueplo AP, Billaud E, Baudin E, Luton JP \& Plouin PF 2002 Effects of slow-release octreotide on urinary metanephrine excretion and plasma chromogranin A and catecholamine levels in patients with malignant or recurrent phaeochromocytoma. Clinical Endocrinology 57 629-634.

Lehnert H, Mundschenk J \& Hahn K 2004 Malignant pheochromocytoma. Frontiers of Hormone Research $\mathbf{3 1}$ 155-162.

Lenders JW, Pacak K, Walther MM, Linehan WM, Mannelli M, Friberg P, Keiser HR, Goldstein DS \& Eisenhofer G 2002 Biochemical diagnosis of pheochromocytoma: which test is best? Journal of the American Medical Association 287 1427-1434.

Linnoila RI, Keiser HR, Steinberg SM \& Lack EE 1990 Histopathology of benign versus malignant sympathoadrenal paragangliomas: clinicopathologic study of 120 cases including unusual histologic features. Human Pathology 21 $1168-1180$.

Loh KC, Fitzgerald PA, Matthay KK, Yeo PP \& Price DC 1997 The treatment of malignant pheochromocytoma with iodine131 metaiodobenzylguanidine $\left({ }^{131} \mathrm{I}\right.$-MIBG): a comprehensive review of 116 reported patients. Journal of Endocrinological Investigation 20 648-658.

McNeil AR, Blok BH, Koelmeyer TD, Burke MP \& Hilton JM 2000 Phaeochromocytomas discovered during coronial autopsies in Sydney, Melbourne and Auckland. Australian and New Zealand Journal of Medicine 30 648-652.

Maloney A \& Workman P 2002 HSP90 as a new therapeutic target for cancer therapy: the story unfolds. Expert Opinion in Biological Therapeutics 2 3-24.

Manger WM \& Gifford RW 1996 Clinical and Experimental Pheochromocytoma. Cambridge, MA: Blackwell Science. 
Matthay KK, DeSantes K, Hasegawa B, Huberty J, Hattner RS, Ablin A, Reynolds CP, Seeger RC, Weinberg VK \& Price D 1998 Phase I dose escalation of ${ }^{131}$ I-metaiodobenzylguanidine with autologous bone marrow support in refractory neuroblastoma. Journal of Clinical Oncology 16 229-236.

Mishra AK, Agarwal G, Kapoor A, Agarwal A, Bhatia E \& Mishra SK 2000 Catecholamine cardiomyopathy in bilateral malignant pheochromocytoma: successful reversal after surgery. International Journal of Cardiology 76 89-90.

Miskulin J, Shulkin BL, Doherty GM, Sisson JC, Burney RE \& Gauger PG 2003 Is preoperative iodine 123 metaiodobenzylguanidine scintigraphy routinely necessary before initial adrenalectomy for pheochromocytoma? Surgery 134 913-922.

Montaldo PG, Raffaghello L, Guarnaccia F, Pistoia V, Garaventa A \& Ponzoni M 1996 Increase of metaiodobenzylguanidine uptake and intracellular half-life during differentiation of human neuroblastoma cells. International Journal of Cancer 67 95-100.

Morikawa T, Suzuki M, Unno M, Endo K, Katayose Y \& Matsuno S 2001 Malignant pheochromocytoma with hepatic metastasis diagnosed 10 years after a resection of the primary incidentaloma adrenal lesion: report of a case. Surgery Today 31 80-84.

Mundschenk J, Unger N, Schulz S, Hollt V, Steinke R \& Lehnert H 2003 Somatostatin receptor subtypes in human pheochromocytoma: subcellular expression pattern and functional relevance for octreotide scintigraphy. Journal of Clinical Endocrinology and Metabolism 88 5150-5157.

Neumann DR, Basile KE, Bravo EL, Chen EQ \& Go RT 1996 Malignant pheochromocytoma of the anterior mediastinum: PET findings with $\left[{ }^{18} \mathrm{~F}\right] \mathrm{FDG}$ and $82 \mathrm{Rb}$. Journal of Computational Assisted Tomography 20 312-316.

Neumann HP, Bausch B, McWhinney SR, Bender BU, Gimm O, Franke G, Schipper J, Klisch J, Altehoefer C, Zerres K, Januszewicz A, Eng C, Smith WM, Munk R, Manz T, Glaesker S, Apel TW, Treier M, Reineke M, Walz MK, Hoang-Vu C, Brauckhoff M, Klein-Franke A, Klose P, Schmidt H, Maier-Woelfle M, Peczkowska M \& Szmigielski C 2002 Germ-line mutations in nonsyndromic pheochromocytoma. New England Journal of Medicine $\mathbf{3 4 6}$ 1459-1466.

Nonaka K, Makuuchi H, Naruse Y, Kobayashi T \& Goto M 2000 Surgical excision of malignant pheochromocytoma in the left atrium. Japanese Journal of Thoracic Cardiovascular Surgery 48 126-128.

Pacak K, Fojo T, Goldstein DS, Eisenhofer G, Walther MM, Linehan WM, Bachenheimer L, Abraham J \& Wood BJ 2001 Radiofrequency ablation: a novel approach for treatment of metastatic pheochromocytoma. Journal of the National Cancer Institute 93 648-649.

Podsypanina K, Lee RT, Politis C, Hennessy I, Crane A, Puc J, Neshat M, Wang H, Yang L, Gibbons J, Frost P, Dreisbach V, Blenis J, Gaciong Z, Fisher P, Sawyers C, HedrickEllenson L \& Parsons R 2001 An inhibitor of mTOR reduces neoplasia and normalizes p70/S6 kinase activity in Pten + /mice. PNAS 98 10320-10325.

Powers JF, Evinger MJ, Tsokas P, Bedri S, Alroy J, Shahsavari M \& Tischler AS 2000 Pheochromocytoma cell lines from heterozygous neurofibromatosis knockout mice. Cell and Tissue Research 302 309-320.

Powers JF, Schelling K, Brachold JM, Tsokas P, Schayek H, Friedman E \& Tischler AS 2002 High-level expression of receptor tyrosine kinase Ret and responsiveness to Retactivating ligands in pheochromocytoma cell lines from neurofibromatosis knockout mice. Molecular and Cellular Neuroscience 20 382-389.

Rao F, Keiser HR \& O'Connor DT 2000 Malignant pheochromocytoma. Chromaffin granule transmitters and response to treatment. Hypertension 36 1045-1052.

Rose B, Matthay KK, Price D, Huberty J, Klencke B, Norton JA \& Fitzgerald PA 2003 High-dose 131Imetaiodobenzylguanidine therapy for 12 patients with malignant pheochromocytoma. Cancer 98 239-248.

Safford SD, Coleman RE, Gockerman JP, Moore J, Feldman JM, Leight GS Jr, Tyler DS \& Olson JA Jr 2003 Iodine-131 metaiodobenzylguanidine is an effective treatment for malignant pheochromocytoma and paraganglioma. Surgery 134 956-962.

Salmenkivi K, Haglund C, Arola J \& Heikkila P $2001 a$ Increased expression of tenascin in pheochromocytomas correlates with malignancy. American Journal of Surgical Pathology 25 1419-1423.

Salmenkivi K, Haglund C, Ristimaki A, Arola J \& Heikkila P $2001 b$ Increased expression of cyclooxygenase-2 in malignant pheochromocytomas. Journal of Clinical Endocrinology and Metabolism 86 5615-5619.

Salmenkivi K, Heikkila P, Liu J, Haglund C \& Arola J 2003 VEGF in 105 pheochromocytomas: enhanced expression correlates with malignant outcome. Apmis 111 458-464.

Sausville EA, Tomaszewski JE \& Ivy P 2003 Clinical development of 17-allylamino, 17-demethoxygeldanamycin. Current Cancer Drug Targets 3 377-383.

Schlumberger M, Gicquel C, Lumbroso J, Tenenbaum F, Comoy E, Bosq J, Fonseca E, Ghillani PP, Aubert B, Travagli JP et al. 1992 Malignant pheochromocytoma: clinical, biological, histologic and therapeutic data in a series of 20 patients with distant metastases. Journal of Endocrinological Investigation 15 631-642.

Shapiro B, Sisson JC, Wieland DM, Mangner TJ, Zempel SM, Mudgett E, Gross MD, Carey JE, Zasadny KR \& Beierwaltes WH 1991 Radiopharmaceutical therapy of malignant pheochromocytoma with $\left[{ }^{131} \mathrm{I}\right]$ metaiodobenzylguanidine: results from ten years of experience. Journal of Nuclear and Biological Medicine 35 269-276.

Shapiro B, Gross MD \& Shulkin B 2001 Radioisotope diagnosis and therapy of malignant pheochromocytoma. Trends in Endocrinology and Metabolism 12 469-475.

Sisson JC, Shapiro B, Shulkin BL, Urba S, Zempel S \& Spaulding S 1999 Treatment of malignant pheochromocytomas with 131-I metaiodobenzylguanidine and chemotherapy. American Journal of Clinical Oncology 22 364-370.

Smith-Hicks CL, Sizer KC, Powers JF, Tischler AS \& Costantini F 2000 C-cell hyperplasia, pheochromocytoma and sympathoadrenal malformation in a mouse model of multiple endocrine neoplasia type 2B. EMBO Journal 19 612-622.

Takahashi K, Ashizawa N, Minami T, Suzuki S, Sakamoto I, Hayashi K, Tomiyasu S, Sumikawa K, Kitamura K, Eto T \& 
Yano K 1999 Malignant pheochromocytoma with multiple hepatic metastases treated by chemotherapy and transcatheter arterial embolization. Internal Medicine 38 349-354.

Tanaka S, Ito T, Tomoda J, Higashi T, Yamada G \& Tsuji T 1993 Malignant pheochromocytoma with hepatic metastasis diagnosed 20 years after resection of the primary adrenal lesion. Internal Medicine 32 789-794.

Tenenbaum F, Lumbroso J, Schlumberger M, Mure A, Plouin PF, Caillou B \& Parmentier C 1995 Comparison of radiolabeled octreotide and meta-iodobenzylguanidine (MIBG) scintigraphy in malignant pheochromocytoma. Journal of Nuclear Medicine 36 1-6.

Thompson LD 2002 Pheochromocytoma of the adrenal gland scaled score (PASS) to separate benign from malignant neoplasms: a clinicopathologic and immunophenotypic study of 100 cases. American Journal of Surgical Pathology 26 $551-566$.

Troncone L, Rufini V, Daidone MS, De Santis M \& Luzi S 1991 $\left[{ }^{131} \mathrm{I}\right]$ Metaiodobenzylguanidine treatment of malignant pheochromocytoma: experience of the Rome group. Journal of Nuclear and Biological Medicine 35 295-299.

Walther MM, Herring J, Enquist E, Keiser HR \& Linehan WM 1999 Von Recklinghausen's disease and pheochromocytomas. Journal of Urology 162 1582-1586.

Wiseman GA \& Kvols LK 1995 Therapy of neuroendocrine tumors with radiolabeled MIBG and somatostatin analogues. Seminars in Nuclear Medicine 25 272-278.
Yon L, Guillemot J, Montero-Hadjadje M, Grumolato L, Leprince J, Lefebvre H, Contesse V, Plouin PF, Vaudry H \& Anouar Y 2003 Identification of the secretogranin II-derived peptide EM66 in pheochromocytomas as a potential marker for discriminating benign versus malignant tumors. Journal of Clinical Endocrinology and Metabolism 88 2579-2585.

Yoshida S, Hatori M, Noshiro T, Kimura N \& Kokubun S 2001 Twenty-six-years' survival with multiple bone metastasis of malignant pheochromocytoma. Archives of Orthopedic Trauma and Surgery 121 598-600.

You MJ, Castrillon DH, Bastian BC, O'Hagan RC, Bosenberg MW, Parsons R, Chin L \& DePinho RA 2002 Genetic analysis of Pten and Ink4a/Arf interactions in the suppression of tumorigenesis in mice. PNAS 99 1455-1460.

Zerhouni E 2003 Medicine. The NIH Roadmap. Science 302 63-72.

Zielke A, Bresalier RS, Siperstein AE, Clark OH, Rothmund M \& Duh QY 1998 A unique allogenic model of metastatic pheochromocytoma: PC12 rat pheochromocytoma xenografts to nude mice and establishment of metastases-derived PC12 variants. Clinical and Experimental Metastasis 16 341-352.

Zielke A, Middeke M, Hoffmann S, Colombo-Benkmann M, Barth P, Hassan I, Wunderlich A, Hofbauer LC \& Duh QY 2002 VEGF-mediated angiogenesis of human pheochromocytomas is associated to malignancy and inhibited by anti-VEGF antibodies in experimental tumors. Surgery 132 1056-1063. 